\title{
Circadian excretory rhythms in night workers
}

\author{
R. T. W. L. CONROY', A. L. ELLIOTT, and J. N. MILLS \\ Department of Physiology, University of Manchester, M13 9PL
}

\begin{abstract}
Conroy, R. T. W. L., Elliott, A. L., and Mills, J. N. (1970). Brit. J. industr. Med., 27, 356-363. Circadian excretory rhythms in night workers. Urine samples have been collected from day and night shift workers in a light engineering factory over periods of 24 or $\mathbf{4 8}$ hours during which blood was also collected for determination of plasma 11-hydroxycorticosteroids (11-OHCS). Different subjects divided their 24-hour output into as few as 4 or as many as 14 portions. Where possible, the timing of the excretory rhythms was assessed objectively by fitting a sine curve. The potassium excretory rhythm was, in most subjects, well adapted to night work in that they excreted least during their hours of sleep; no relationship could be discerned between potassium excretory and plasma 11-OHCS rhythms. The sodium excretory rhythm was less regular than that of potassium in both night and day workers, and in night workers both sodium excretion and urine flow were often high during the hours of sleep, so that the subjects were sometimes awakened by the need to micturate. There was, however, sufficient association between the behaviour of sodium and potassium to suggest that their excretory rhythms have a common cause, and that this is not the secretion of 11-OHCS. Phosphate excretion fell sometimes on rising, even though plasma 11-OHCS concentration was not high, and sometimes after a high level of plasma 11-OHCS, at a time other than on rising. This suggests that these are two independent contributory causes of the usual morning fall in phosphate excretion.
\end{abstract}

In our previous paper (Conroy, Elliott, and Mills, 1970) we compared the rhythms in plasma corticosteroid concentration of a group of night shift workers in a light engineering works with those of a group of day workers in the same factory. The subjects produced serial urine samples on the same occasions, and their electrolyte excretory rhythms are described in this paper.

\section{Subjects and experimental procedure}

The designation of the groups of subjects is the same as in our previous paper.

Group 1a Eleven night workers were provided with

${ }^{1}$ Present address: Department of Physiology, Royal College of Surgeons in Ireland, St. Stephen's Green, Dublin 2. measuring cylinders and small bottles and were asked to record the time and volume of each urination over a period of 24 hours, and to provide us with a sample for analysis.

Group 1b Fifteen night workers, including three from group 1a, were asked similarly to collect serial urine samples over a period of 48 hours.

Groups $2 a$ and b Eight and 12 day workers in the same factory were similarly asked to produce urine samples over continuous periods of 24 hours and 48 hours.

The frequency of voiding varied widely between subjects, so that we received as few as 4 or as many as 14 samples to cover a 24-hour period; some subjects failed to produce samples to cover the whole period requested, and a few samples were lost, so that we had information about the volume but not the composition. The number 
of results presented, therefore, usually falls short of those hoped for.

The day shift was from 07.40 to $16.24 \mathrm{hr}$, the night shift from 22.00 to $07.42 \mathrm{hr}$. The night workers mostly went to bed around 09.00 and slept for 6 to 9 hours, but one reckoned to be in bed by 08.00 , and three did not go to bed until 11.00 or midday. Fourteen of the 23 admitted to being sometimes awakened by the need to micturate, but they did not always record their sleeping urine in two separate portions. Day workers told us that they were rarely thus awakened, and that they were not awakened on any of the nights of the study. No control was attempted over the subjects' habits, fluid intake, or any other aspect of their routine, except that they were asked to collect samples on working days (or nights) rather than at weekends.

\section{Analytical methods}

Sodium and potassium were estimated with a flame photometer (EEL), phosphate by the method of Fiske and Subbarow (1925) modified for use with autodispensers, and creatinine by the method of Bonsnes and Taussky (1945), also modified for use with autodispensers. Creatinine excretion was used in the manner indicated by Mills, Thomas, and Yates (1955) as a check on bladder emptying. Erratic and abrupt changes in creatinine excretion, especially when other urinary constituents behaved similarly, were taken as evidence of incomplete voiding.

\section{Treatment of findings}

To define objectively the timing and amplitude of suspected excretory rhythms, sine curves were fitted to the findings. Whittaker and Robinson (1926) described a procedure for fitting such a curve to a series of 12 measurements equally spaced in time. To use this method for irregularly spaced data such as ours, the mean rate of excretion over each two hours has been calculated, and this is treated as the instantaneous excretion at the midpoint of the period. We have also used a computer programme which fits a sine curve to any number of measurements equally spaced in time. For this the different collection periods are divided into small units: for example, if the mean excretion rate over $1 \frac{1}{4}$ hours were $x$, and over the next $5 \frac{1}{2}$ hours $y$, these could be treated as a series of 15-minute collection periods, five of them at an excretory rate of $x$, followed by 22 at an excretory rate of $y$.

\section{Results}

A simple assessment of electrolyte excretory rhythms may be gained by noting whether or not an actual minimum level of excretion occurred during sleep, as is usual in subjects on a nychthemeral routine. Table 1 shows that by this criterion night workers and day workers were equally well adapted to their own hours of work and sleep; in both groups, potassium excretion was more regular than that of sodium, but these two kations otherwise followed a similar rhythm. Thus, if potassium excretion was not
TABLE 1

Occasions When Sodium AND Potassium Excretion Were Minimal during Sleep, AND When PhOSPHATE EXCRETION FELl ON WAKING

\begin{tabular}{|c|c|c|c|c|}
\hline & & $\begin{array}{c}\text { No. of } \\
\text { subjects }\end{array}$ & $\begin{array}{c}\text { No. of } \\
\text { nychthemera }\end{array}$ & $\begin{array}{l}\text { No. of } \\
\text { occasions } \\
\text { when } \\
\text { excretion } \\
\text { was } \\
\text { minimal }\end{array}$ \\
\hline $\begin{array}{l}\text { Sodium } \\
\text { Day workers ... } \\
\text { Night workers.. }\end{array}$ & $\begin{array}{l}\cdots \\
\ldots\end{array}$ & $\begin{array}{l}13 \\
23\end{array}$ & $\begin{array}{l}20 \\
41\end{array}$ & $\begin{array}{r}9 \\
20\end{array}$ \\
\hline \multirow[t]{2}{*}{$\begin{array}{l}\text { Potassium } \\
\text { Day workers .. } \\
\text { Night workers. . }\end{array}$} & $\begin{array}{l}\ldots \\
\ldots\end{array}$ & $\begin{array}{l}13 \\
23\end{array}$ & $\begin{array}{l}20 \\
41\end{array}$ & $\begin{array}{l}13 \\
29\end{array}$ \\
\hline & & & & $\begin{array}{c}\text { No. of } \\
\text { occasions } \\
\text { when } \\
\text { excretion } \\
\text { fell on } \\
\text { waking }\end{array}$ \\
\hline $\begin{array}{l}\text { Phosphate } \\
\text { Day workers .. } \\
\text { Night workers.. }\end{array}$ & $\begin{array}{l}\ldots \\
\ldots\end{array}$ & $\begin{array}{l}13 \\
21\end{array}$ & $\begin{array}{l}20 \\
36\end{array}$ & $\begin{array}{l}18 \\
25\end{array}$ \\
\hline
\end{tabular}

TABLE 2

Total Volume of Urine Produced and RATE of Sodium EXCRETION DURING PERIOD OF SleEP IN DAy Workers, AND IN Night WORKERS WHEN SLEEP WAS UNINTERRUPTED aNd WHEN SLeEP WAS BRoken By NeED TO Micturate

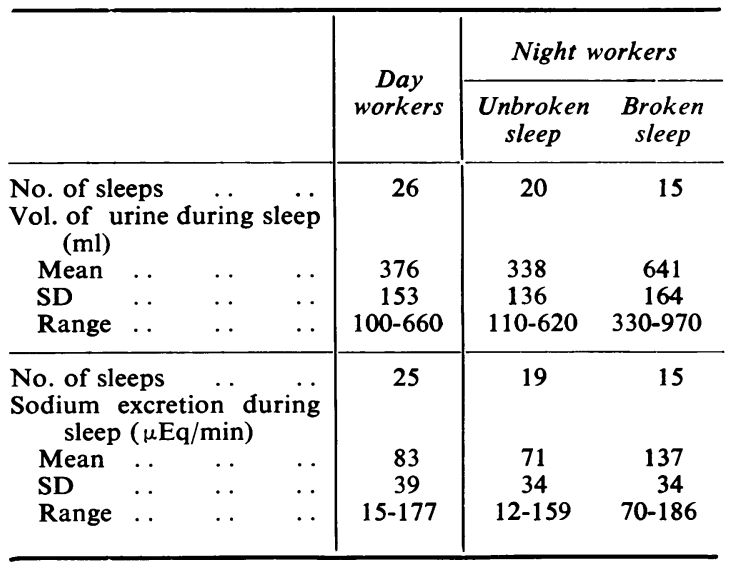




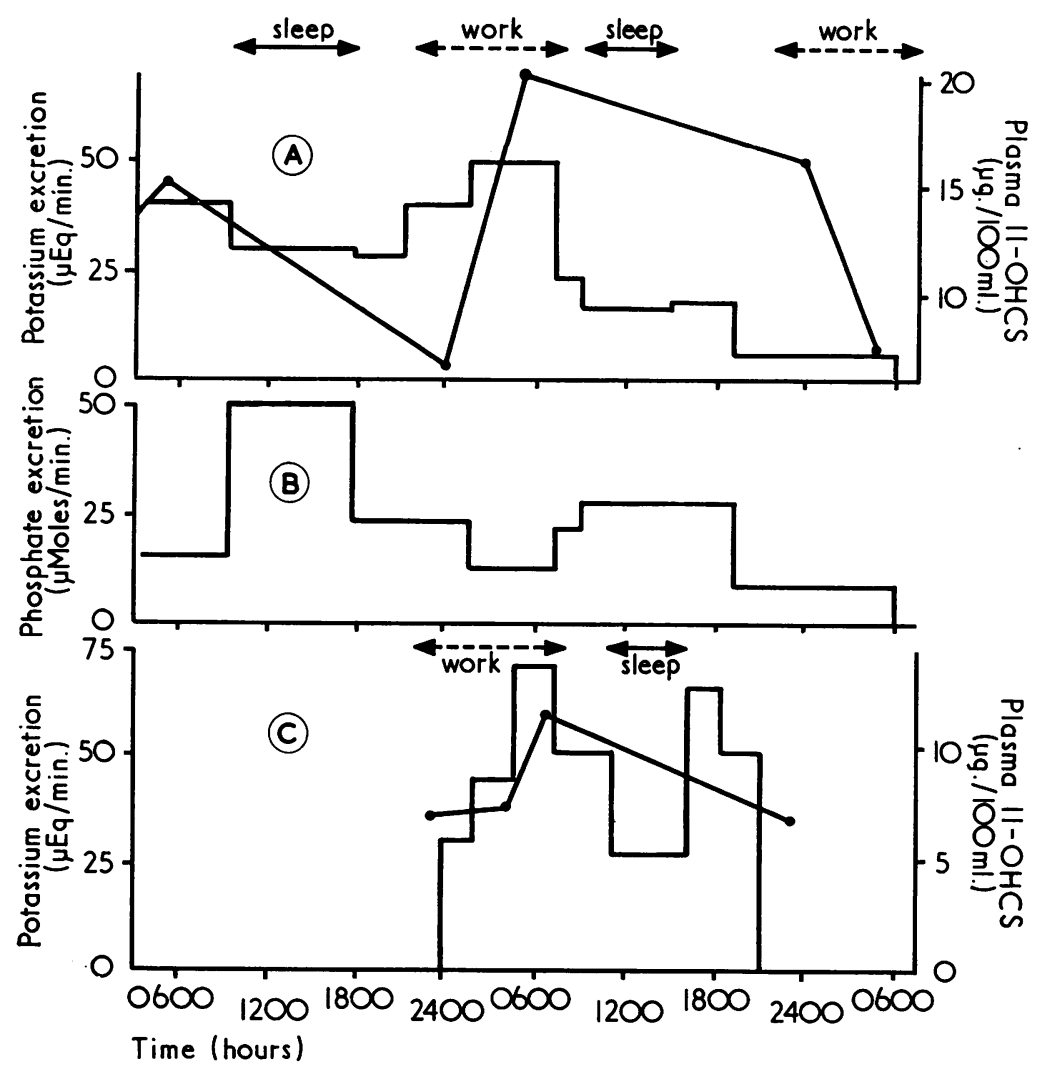

FIG. 1. Potassium excretion and plasma corticosteroid concentration in two night workers. A, no recurrent excretory pattern in two consecutive 24-hr periods. C, bi-modal potassium excretory pattern, with characteristic 'day' pattern in plasma steroids. B, Phosphate excretion in the same subject as A, high during sleep and falling during work period.

minimal during sleep, then neither was sodium, uniformly in day workers and on 10 out of 12 occasions in night workers. Night workers sometimes showed two excretory minima for potassium or sodium, one during sleep and the other during the night. Figure 1C shows an example of two nearly equal minima, while Fig. 4A illustrates a subject whose lowest potassium excretion is during sleep, but who has a secondary minimum at night around the time when excretion is lowest in day workers.

In so far as most of them excreted least electrolyte while they were sleeping, these night workers seemed reasonably adapted to their routine. Of those whose minimal potassium excretion was not during the sleep period, however, day workers nearly always excreted least in the period immediately before sleep, and night workers immediately after sleep.
The minimum was thus in the late evening in both these groups, suggesting a consistent circadian influence. When subjects were observed on two consecutive nychthemera, potassium excretion usually followed a similar pattern in both (16 of 22 instances), but sodium was much less consistent, repeating its pattern on only 9 out of 22 occasions. In this respect there was no difference between day and night workers.

Phosphate excretion usually falls on waking, or early in the morning in subjects who stay awake (see Mills (1966) for extensive bibliography). In this respect the day workers behaved more regularly than did the night workers, since their excretion fell on waking 18 out of 20 times, in contrast with only 25 out of 36 times in the night workers (Table 1). This difference between day and night workers is 


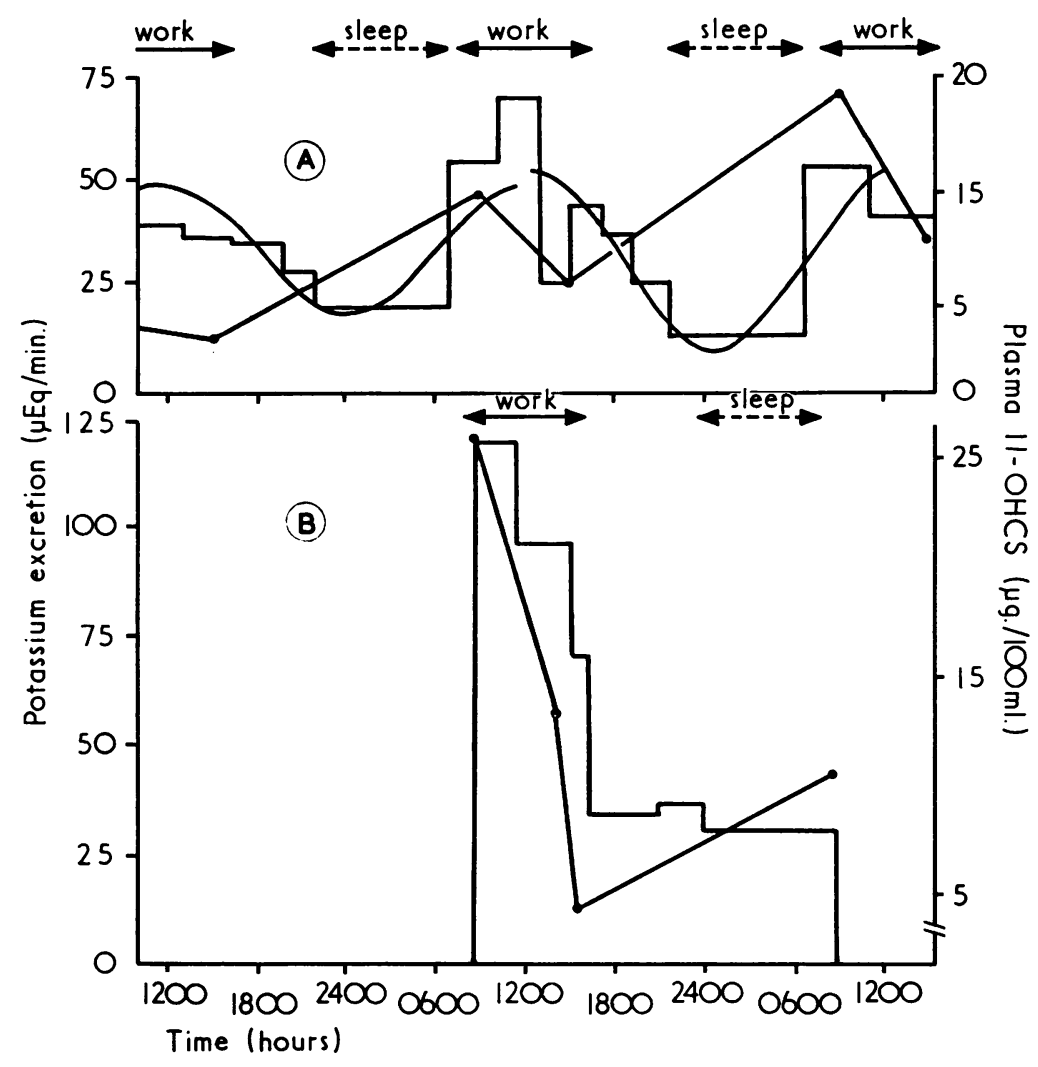

FIG. 2. Potassium excretion and plasma corticosteroid concentration in two day workers. In $\mathbf{A}$, sine curves have been fitted to the excretory data for each 24-hr period.

barely significant $(P=0.066$ by the exact test of Fisher (1941)). As has been mentioned above, whereas potassium and sodium excretory patterns were usually regular in the same night workers, there was no such association between the rhythm of these kations and the expected pattern of phosphate excretion: both might be regular, both anomalous, or one regular and the other anomalous.

While electrolyte excretory rhythms thus appeared fairly well adapted to night work in these subjects, an inadequate adaptation is suggested by the common observation that the sleep of night workers is often broken through the need to micturate. Fourteen of the 23 night workers told us that they suffered in this way, though it seemed from those whom we studied on three separate nights that their sleep was sometimes undisturbed. In Table 2 it can be seen that when night workers slept uninterruptedly their urine volume was no greater than that produced during the nocturnal sleep of day workers, whilst interrupted sleep was associated with considerably greater urine volumes. There is a wide overlap, however, between the groups, indicating considerable variation in the volume of urine which the bladder could accommodate without awakening the subject. This is hardly surprising as neither the fluid intake before sleep, nor other disturbing factors such as light and noise, were subject to any experimental control.

Sodium is one of the more important osmotic constituents of urine, and other studies (Mills and Stanbury, 1952; Mills, 1966) have suggested that the renal excretory rhythm may in part be determined osmotically by the rhythm in sodium excretion. Table 2 suggests that this is so, since the sodium excretion in subjects awakened by a large urinary volume was higher than in those who slept uninterruptedly, whether night or day workers.

The usual method for objective specification of a supposed rhythm is to fit a sine curve to the results. Since potassium excretion was more regular than that of sodium, we have fitted such curves, with a 


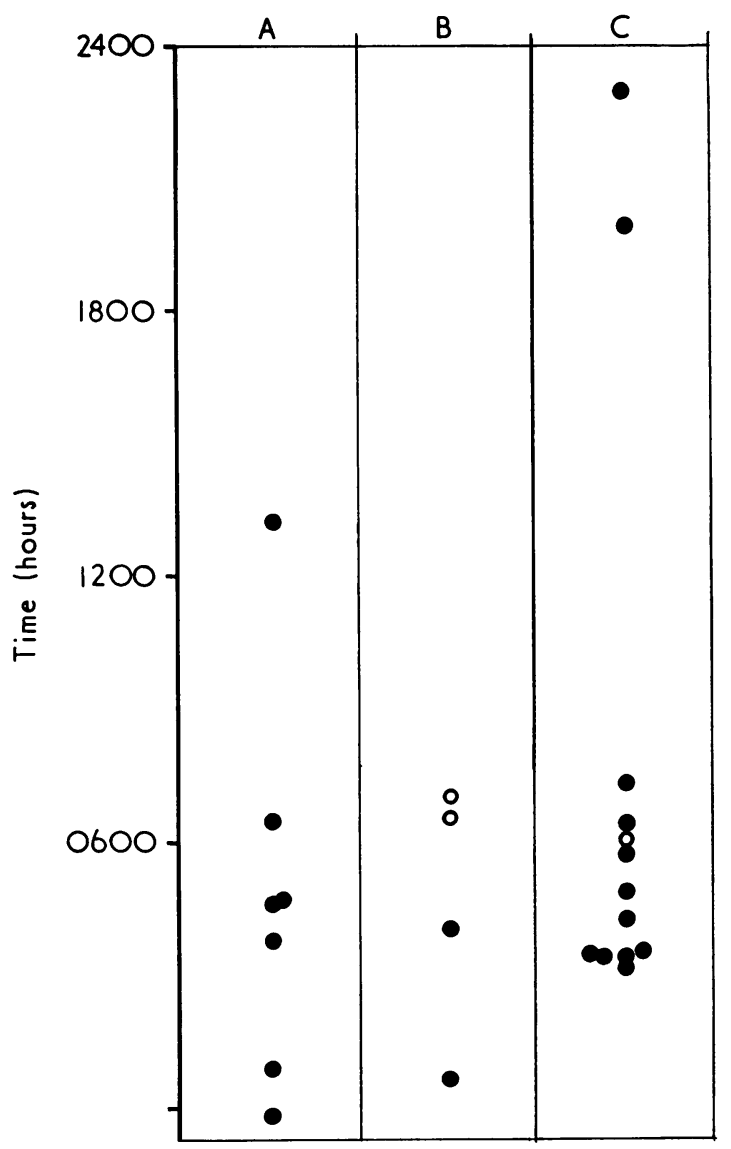

FIG. 3. Time of maximum excretion of potassium in night workers, assessed from best-fitting sine curve, $\mathrm{C}$ assessed by eye. $\mathbf{A}, \mathbf{B}$ and $\mathbf{C}$, occasions when maximum plasma corticosteroid concentration was around midnight, 04.00 or 06.00 respectively.

period of $24 \mathrm{hr}$, to as many of the nychthemera as seemed profitable. For some nychthemera this procedure would clearly be inapplicable. Figure 1A shows a 48-hr series in which, though a sine curve might be fitted to the first $24 \mathrm{hr}$, the pattern fails to repeat itself in the following $24 \mathrm{hr}$ : and in Fig. 1C the excretory pattern is non-sinusoidal since there are minima both during sleep and during the night. Some series did not cover a full $24 \mathrm{hr}$ : and in some, as illustrated in Fig. 2B, the rate of excretion in the last period was so different from that in the first that one cannot confidently assume the existence of a rhythm. Some subjects divided their 24-hr output into too few portions: the potassium and sodium excretions shown in Fig. 4B and $\mathrm{C}$ conform reasonably to a sine curve, but as three parameters are needed to define the curve it could hardly have any acceptable level of significance as only four or five urine samples were collected in each $24 \mathrm{hr}$. Figure 5 shows the potassium excretory pattern in a subject who voided 12 times in $24 \mathrm{hr}$, with the sine curve which can be fitted to such results with reasonable confidence. Fitted sine curves are similarly shown in Figures $2 \mathrm{~A}$ and $4 \mathrm{~A}$.

It has been suggested (see Discussion for references) that the rhythmic secretion of cortisol is responsible for the rhythm in potassium excretion. As shown in Fig. 2, plasma steroid concentration in day workers is highest in the early morning, and potassium excretion is greatest early or late in the morning and lowest at night while the subject is asleep. In night workers this usual association between the adrenal and renal rhythms no longer obtains. In Fig. 3 the times of peak potassium excretion, either mathematically computed from the best fitting sine curve or, when this was not possible, estimated visually, are grouped into those from subjects with different forms of plasma steroid rhythm. Potassium excretion was usually highest during the nocturnal hours of work, whether the peak plasma steroid concentration was around midnight, 04.00 or $06.00 \mathrm{hr}$.

Figures 4A and 5 show examples of a potassium excretory rhythm well adapted to night work but a plasma steroid concentration low on starting work and high on finishing in the early morning, as one would expect in a day worker. Figures 4B and C show excretory rhythms for potassium and sodium similarly adapted to night work but with the steroid rhythm also adapted. When excretion or plasma steroids behaved irregularly (Fig. 1A and C) there was again no apparent sequence of high steroid concentration and high potassium excretion shortly afterwards.

Phosphate excretion normally falls on waking, and since cortisol and other glucocorticoids are known to lower plasma phosphate concentration (Ingbar, Kass, Burnett, Relman, Burrows, and Sisson, 1951; Frawley, 1955; Kupperman, Persky, Linsk, Isaacs, and Rosenbluth, 1955; Mills and Thomas, 1957a, 1959), and hence renal excretion of phosphate, the hypothesis of a causal connexion is plausible. In many subjects the adrenal rhythm was out of phase with the sleeping habits, and the plasma steroid concentration was not high around the time of waking; we have therefore examined the data for phosphate excretion. Unfortunately, the urine collection periods were often too long for any accurate specification of the time when phosphate excretion fell abruptly. There were, however, seven series of observations in which phosphate excretion fell sharply shortly after a steroid peak (Fig. 6), and in three of these phosphate excretion did not fall when the subject rose from sleep. In contrast, on four occasions phosphate excretion fell when the 


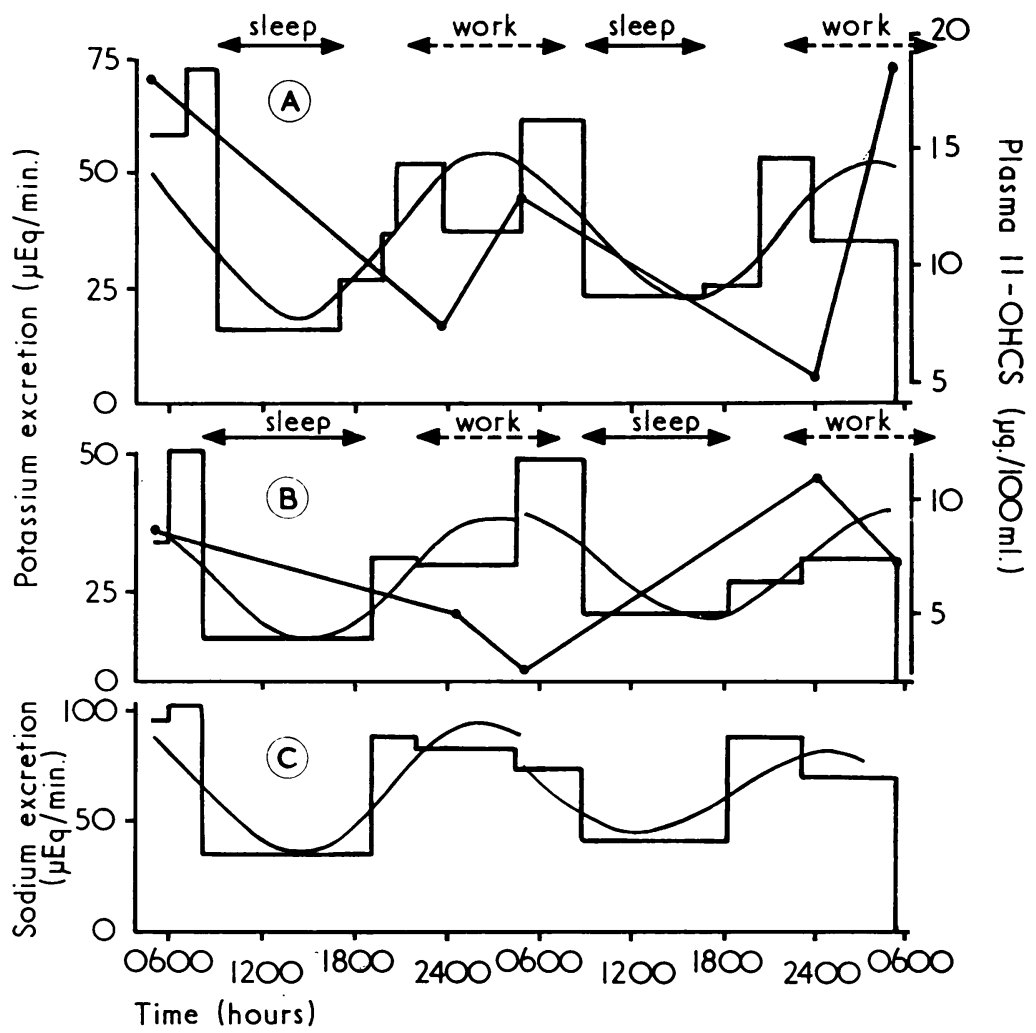

FIG. 4. Urinary excretion rates and plasma corticosteroid concentrations over $24 \mathrm{hr}$ in night workers.

A, potassium excretion in a subject whose electrolyte excretion followed a nocturnal, and steroid concentration a diurnal, pattern.

$B$, potassium and $C$, sodium excretion in a subject whose electrolyte excretion and steroid concentration both followed a nocturnal pattern.

Best-fitting sine curves for the excretory data are added.

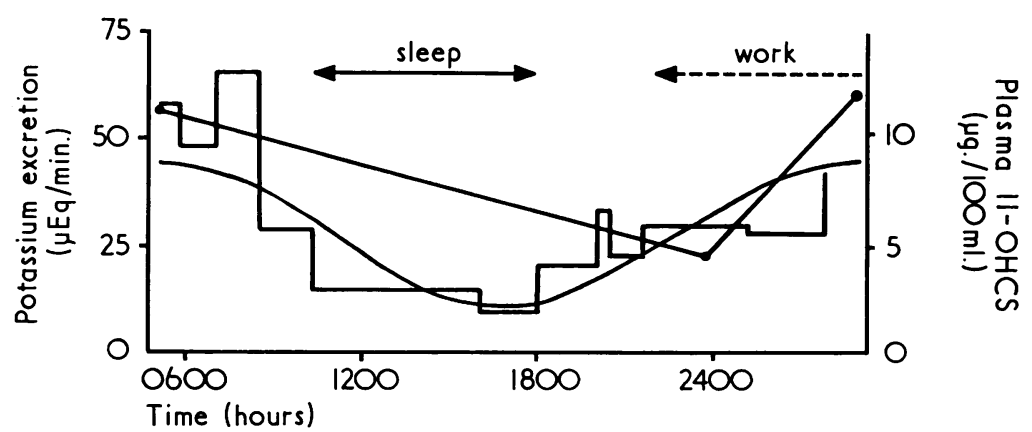

FIG. 5. Plasma corticosteroid concentration and renal potassium excretion over $24 \mathrm{hr}$ in a night worker, with best-fitting sine curve for the excretory data. 


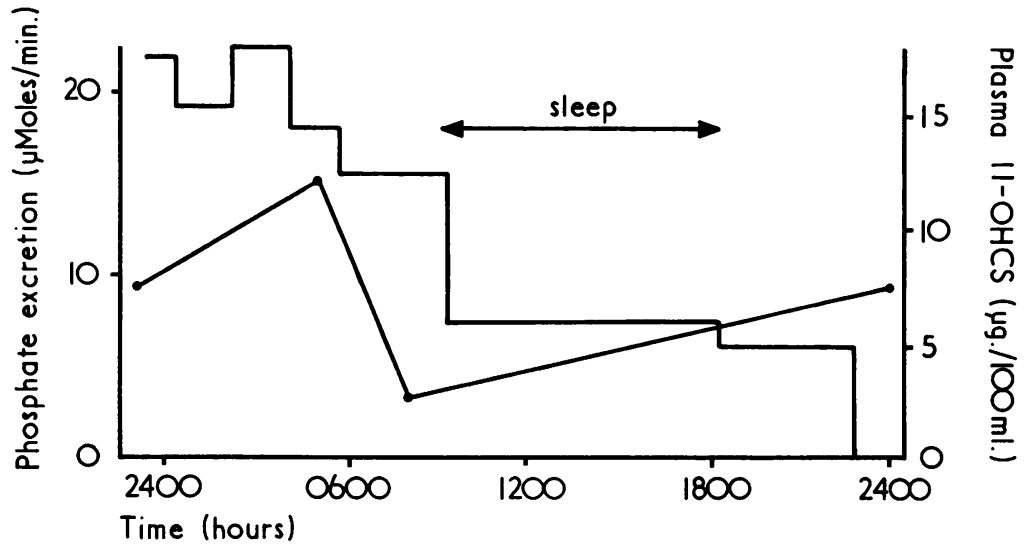

FIG. 6. Plasma corticosteroid concentration and renal phosphate excretion over $24 \mathrm{hr}$ in a night worker.

subject rose from sleep but not after his plasma steroid concentration had reached a high level (Fig. 1B).

\section{Discussion}

We have found very little mention of the renal excretory rhythms of night workers. Mills and Thomas (1957b) found that a subject who had been working on a night shift for four weeks had retained a diurnal phasing of his potassium and sodium excretory rhythms; his phosphate excretion, however, at the end of the four weeks fell when he arose from diurnal sleep, and when he returned to his usual habits it immediately reverted to the usual timing. Kojima and Niiyama (1965) found, in a group of four young and four older steel workers who changed their shifts every five days, that the potassium excretory rhythm was disturbed but not altered to correspond with the times of work, whilst sodium excretion adhered to a diurnal pattern. Lobban and Tredre (1966) found a large number of irregular excretory patterns in a group of workers with entirely irregular hours. In contrast, the coalminers of Spitsbergen, living in an isolated community whose social life is geared to the work in the mines and in a region where for most of the year there is no alternation of day and night, had excretory rhythms fully adapted to their hours of work (Lobban, 1963, 1965).

Our subjects showed potassium excretory rhythms well adlpted to night work, in that the phase of their rhythms was in accord with their hours of work and sleep. Sodium behaved in much the same way but less regularly, as in subjects living on normal time or on other abnormal time routines. Their adrenals, as reported in the previous paper, were much less well adapted. It has often been speculated or supposed (Doe, Flink, and Goodsell, 1956; Martel, Sharp, Slorach, and Vipond, 1962; Imrie, Mills, and Williamson, 1963a; Vagnucci, Shapiro, and McDonald, 1969) that the adrenal rhythm governs that of the kidney, but other observations contradict this supposition (Nabarro, 1956; Imrie, Mills, and Williamson, 1963b; Simpson and Lobban, 1967) as does our work reported here. Some indication of a persistence of normal diurnal phasing is offered by the frequent low electrolyte excretion in the hours before midnight. The tendency to a high sodium excretion and high urine flow during sleep is an indication that the amplitude of the excretory rhythm is less well adapted than the phase.

Our observations provide some clues on the means whereby rhythmical habits, or an endogenous clock, control renal behaviour. Since they are so commonly associated, it appears that sodium and potassium excretion have a common controlling mechanism, and that this is not the adrenal secretion of 11hydroxycorticosteroids. The less regular behaviour of sodium may merely reflect the variety of influences which affect its excretion. Further, it appears that the usual morning fall of phosphate excretion may be due in part to increased adrenal secretion and in part to some other influence involved in waking and rising from sleep. Some of these conclusions are in accord, some at variance, with other published work, but all need testing under more stringent conditions, better controlled than was possible in the circumstances of the present observations.

If we attempt to use such physiological findings as an indication of how well one or another group of men, or one or another shift system, is fitted to night 
work, we enter uncertain territory. Renal behaviour is obviously of practical importance when it leads to interruption of sleep, but we are completely ignorant how far an adapted rhythm in potassium excretion, or in adrenal secretion, conduces to working efficiency or to well-being.

Attempts have been made to relate the adaptation of body temperature rhythms (Teleky, 1943; Van Loon, 1963; Colquhoun, Blake, and Edwards, 1968) or of renal excretory rhythms (Lobban and Tredre, 1966) to a satisfactory adjustment to unusual hours of work. Rhythms in single parameters are unlikely to provide an adequate criterion, and further studies should have regard to a range of physiological factors and also to psychological and sociological ones.

The authors wish to acknowledge the co-operation of the workers who so readily volunteered to give blood samples; and of the managements and medical staffs of the engineering and newspaper printing works.

Our thanks are due also to Miss M. Hall for her skilled technical assistance.

\section{References}

Bonsnes, R. W., and Taussky, H. H. (1945). On the colorimetric determination of creatinine by the Jaffe reaction. J. biol. Chem. 158, 581-591.

Colquhoun, W. P., Blake, M. J. F., and Edwards, R. S. (1968). Experimental studies of shift-work. 1: A comparison of 'rotating' and 'stabilized' 4-hour shift systems. Ergonomics, 11, 437-453.

Conroy, R. T. W. L., Elliott, A. L., and Mills, J. N. (1970). Circadian rhythms in plasma concentration of 11-hydroxy corticosteroids in men working on night shift and in permanent night workers. Brit. J. industr. Med., 27, 170-174.

Doe, R. P., Flink, E. B., and Goodsell, M. G. (1956). Relationship of diurnal variation in 17-hydroxycorticosteroid levels in blood and urine to eosinophils and electrolyte excretion. J. clin. Endocr., 16, 196-206.

Fisher, R. A. (1941). Statistical Methods for Research Workers. 8th ed., Oliver and Boyd, Edinburgh.

Fiske, C. H., and Subbarow, Y. (1925). The colorimetric determination of phosphorus. J. biol. Chem., 66, 375-400.

Frawley, T. F. (1955). The role of the adrenal cortex in glucose and pyruvic acid metabolism in man, including the use of intravenous hydrocortisone in acute hypoglycemia. Ann. N.Y. Acad. Sci., 61, 464-493.

Imrie, M. J., Mills, J. N., and Williamson, K. S. (1963a). Circadian variations in renal and adrenal function: are they connected? Mem. Soc. Endocr., 13, 3-13.
- - - and - (1963b). The renal action of small doses of cortisol at night. J. Endocr., 27, 289-292.

Ingbar, S. H., Kass, E. H., Burnett, C. H., Relman, A. S., Burrows, B. A., and Sisson, J. H. (1951). The effects of ACTH and cortisone on the renal tubular transport of uric acid, phosphorus, and electrolytes in patients with normal renal and adrenal function. J. Lab. clin. Med., 38, 533-541.

Kojima, A., and Niiyama, Y. (1965). Diurnal variations of 17ketogenic steroid and catecholamine excretion in adolescent and middle-aged shift workers with special reference to adaptability to night work. Industr. Hlth (Kawasaki), 3, 9-19.

Kupperman, H. S., Persky, M., Linsk, J., Isaacs, M., and Rosenbluth, M. (1955). The paradoxical effect of intravenous hydrocortisone upon carbohydrate metabolism. Ann. N.Y. Acad. Sci., 61, 494-501.

Lobban, M. C. (1963). Human diurnal rhythms in an Arctic mining community. J. Physiol. (Lond.), 165, 75-76 P.

- (1965). Dissociation in human rhythmic functions. In Aschoff, J. (Ed). Circadian Clocks, pp. 219-227. North-Holland Publ. Co., Amsterdam.

- and Tredre, B. E. (1966). Daily rhythms of renal excretion in human subjects with irregular hours of work. J. Physiol. (Lond.), 186, 139-140 P.

Martel, P. J., Sharp, G. W. G., Slorach, S. A., and Vipond, H. J. (1962). A study of the roles of adrenocortical steroids and glomerular filtration rate in the mechanism of the diurnal rhythm of water and electrolyte excretion. J. Endocr., 24, 159-169.

Mills, J. N. (1966). Human circadian rhythms. Physiol. Rev., 46, 128-171.

— rhythm on a 12-hour cycle of activity. J. Physiol. (Lond.), 117, 22-37.

- and Thomas, S. (1957a). The acute effect of adrenal hormones and carbohydrate metabolism upon plasma phosphate and potassium concentrations in man. J. Endocr., 16, 164-179.

, - (1957b). Diurnal excretory rhythms in a subject changing from night to day work. $J$. Physiol (Lond.), 137, 65-66 P.

- - (1959). The influence of adrenal corticoids on phosphate and glucose exchange in muscle and liver in man. J. Physiol. (Lond.), 148, 227-239.

,-- , and Yates, P. A. (1955). Assessment of voluntary bladder emptying in man. J. Physiol (Lond.), 129, 408-411.

Nabarro, J. D. N. (1956). The adrenal cortex and renal function. In Modern Views on the Secretion of Urine. Edited by F. R. Winton, pp. 148-185. Churchill, London.

Simpson, H. W., and Lobban, M. C. (1967). Effect of a 21-hour day on the human circadian excretory rhythms of 17-hydroxycorticosteroids and electrolytes. Aerospace Med., 38, 1205-1213.

Teleky, L. (1943). Problems of nightwork: influences on health and efficiency. Industr. Med., 12, 758-779.

Vagnucci, A. H., Shapiro, A. P., and McDonald, R. H. (1969). Effects of upright posture on renal electrolyte cycles. J. appl. Physiol., 26, 720-731.

Van Loon, J. H. (1963). Diurnal body temperature curves in shift workers. Ergonomics, 6, 267-273.

Whittaker, E. T., and Robinson, G. (1926). The Calculus of Observations. 2nd ed., Blackie, London.

Received for publication January 13, 1970 